\title{
Measurements of low-level anthropogenic radionuclides from soils around Maralinga
}

\author{
Stephen G. Tims ${ }^{1,}$ a , Dimitrios Tsifakis ${ }^{1}$, Michaela Srncik $^{1}$, L. Keith Fifield ${ }^{1}$, Gary J. Hancock ${ }^{2}$ and Mario De Cesare ${ }^{1}$ \\ ${ }^{1}$ Department of Nuclear Physics, Research School of Physics and Engineering, Australian National University, Canberra, \\ ACT 0200, Australia \\ ${ }^{2}$ CSIRO Land and Water, Canberra, ACT, Australia
}

\begin{abstract}
The isotopes ${ }^{239} \mathrm{Pu}$ and ${ }^{240} \mathrm{Pu}$ are present in surface soils as a result of global fallout from nuclear weapons tests carried out in the 1950's and 1960's. These isotopes constitute artificial tracers of recent soil erosion and sediment movement. In practice the high throughput capabilities and high sensitivity of the AMS technique makes the study of Australia's geographically large areas viable using Pu isotopes. As part of its weapons development program the United Kingdom carried out a series of atmospheric and surface nuclear weapons tests at Maralinga, South Australia in 1956 and 1957. The contribution from the Maralinga tests to the $\mathrm{Pu}$ isotopic abundances present in the region around Maralinga is largely unknown. In global fallout, for example, the ${ }^{240} \mathrm{Pu} /{ }^{239} \mathrm{Pu}$ ratio is typically in the range $0.17-0.19$, but the influence of the regional tests could lead to values outside this range. This would impact on the assessment techniques used in the soil and sediment tracer studies. We report recent measurements on soil samples collected from across the Maralinga Test site.
\end{abstract}

\section{Introduction}

From the point of view of using plutonium as a tracer of soil movement nuclear weapons tests can be divided into two categories: (i) high yield explosions that inject $\mathrm{Pu}$ into the stratosphere, where it remains with a residence half-life of 8 - 24 months [1] and becomes relatively well mixed before returning to the surface as "global fallout", and (ii) low yield detonations $(<\sim 300 \mathrm{kT})$ for which the bulk of the nuclear debris are confined to the troposphere, for a residence half-life estimated at $\sim 70$ days [2] and which leads to "regional fallout" over an area determined largely by the fission yield of the device and by the meteorological conditions at the time of the test and in the period thereafter. Fallout in the immediate vicinity of tests carried out close to ground level can also have relatively large particles derived from bomb fragments or contaminated ground material that are deposited from the atmosphere as "local fallout" within hours or days of the test [3]. The final relative amounts of the $\mathrm{Pu}$ isotopes from each test depend on the individual weapon design and yield, hence local and regional fallout can have plutonium isotopic signatures that differ significantly from that of global fallout.

Between 1952 and 1957 twelve nuclear weapons were detonated in Australia, with an average yield of $\sim 15 \mathrm{kT}$ equivalent TNT. These tests were carried out at three sites: at the Montebello Islands, off the coast of Western
Australia (3 tests), and in South Australia at Emu field (2 tests) and Maralinga (7 tests). In addition to the nuclear detonations at Maralinga there were also numerous safety trials that involved the burning and/or dispersal by conventional explosives of plutonium, uranium, and other radionuclides [4]. In particular the 12 Vixen B trials, each of which involved approximately $4 \mathrm{TBq}$ of ${ }^{239} \mathrm{Pu}$, left Taranaki the most severely contaminated site at Maralinga, with approximately $22 \mathrm{~kg}$ of ${ }^{239} \mathrm{Pu}$ being distributed across the local environment. This is comparable with the $\sim 30 \mathrm{~kg}$ of ${ }^{239} \mathrm{Pu}$ deposited across the whole of mainland Australia as a result of global fallout derived from all atmospheric tests world-wide.

The Maralinga region sits on a low calcrete rise at $\sim 200 \mathrm{~m}$ altitude north of the Nullarbor Plain, on the southern edge of the Great Victoria Desert. Relief in the area is typically less than $6 \mathrm{~m}$ and average annual rainfall is $200 \mathrm{~mm} \cdot \mathrm{a}^{-1}$. Vegetation is largely open woodland with a low shrub understory, or hummock grassland. Weapons tests at Maralinga were carried out within an area of a few $\mathrm{km}^{2}$, approximately $35 \mathrm{~km}$ to the north of Maralinga village (figure 1 ). The safety trials were conducted at several locations to the south and south-east of the test site, and up to $\sim 30 \mathrm{~km}$ to the north-east of the village. In order to use global fallout $\mathrm{Pu}$ as a tracer of soil movement in Australia the regional fallout component attributable to the Maralinga tests needs to be characterized. This is best achieved using samples collected from close to the test site area, where the signal

\footnotetext{
a Corresponding author: steve.tims@anu.edu.au
} 
is greatest, but outside the region affected by local fallout from the safety trials. While the vast bulk of the local fallout dispersed during the trials was removed during clean-up and rehabilitation projects, the extent of the area where local $\mathrm{Pu}$ fallout is a significant fraction of the total $\mathrm{Pu}$ fallout has not been established. The aim of the present work was to determine optimal sampling locations to avoid local fallout from the trials while maximizing the regional fallout signal from the tests in Australia.

\section{Methods}

Soil cores for the study reported here were collected at approximately $5 \mathrm{~km}$ intervals alongside the access road between Maralinga village and the test site area. Sampling sites were roughly $20-30 \mathrm{~m}$ from the access road, and at the time of collection showed no evidence of anthropogenic disturbance. Eight cores were collected into lengths of tube, each $\sim 100 \mathrm{~mm}$ long and $38 \mathrm{~mm}$ in diameter, sealed at each end and transported intact to the Australian National University (ANU) laboratories for $\mathrm{Pu}$ analysis using Accelerator Mass Spectrometry (AMS).

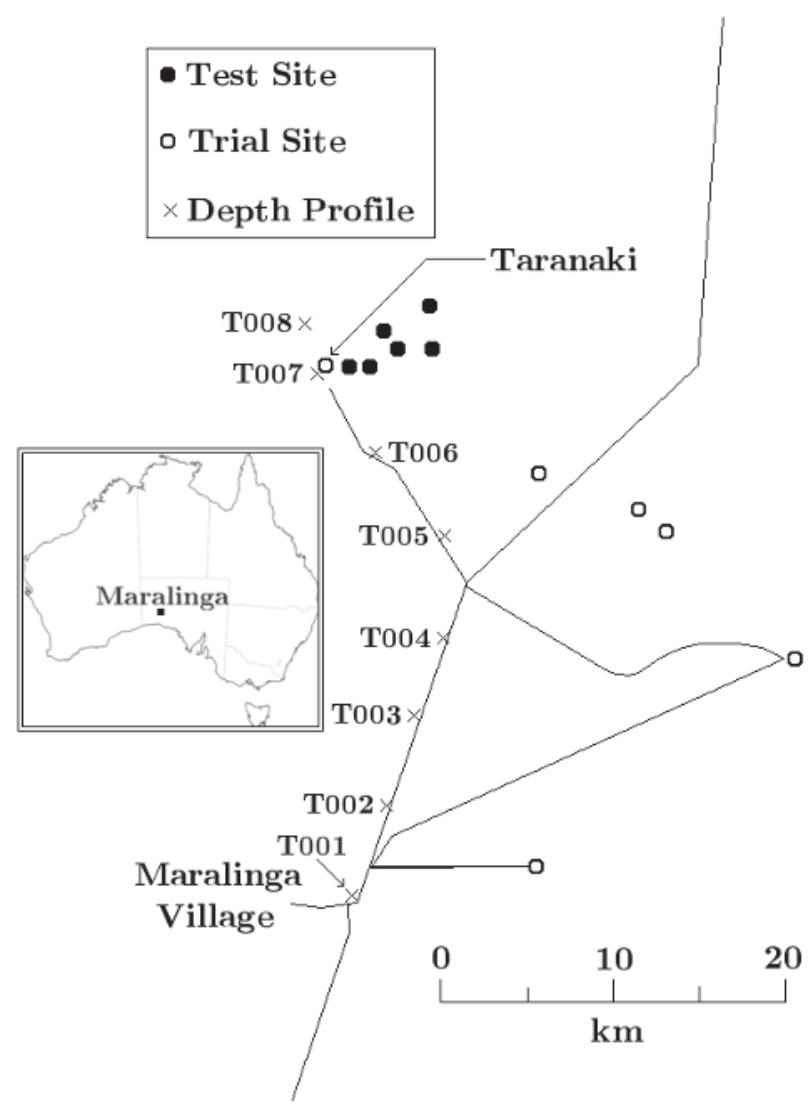

Figure 1. The Maralinga test site area. Crosses indicate approximate sampling locations used in the present work. Sites where weapons tests were carried out are indicated with solid circles, and safety trial locations by open circles. Note that the Taranaki site was also used for the $25 \mathrm{kT}$ Antler round 3 weapons test.

Sample preparation and measurement details were based on those described in [5]. Briefly, each core was first sectioned into $\sim 20 \mathrm{~mm}$ depth increments, and the material from each increment thoroughly mixed to homogenise the sample. The surface sample from each core was then analysed for ${ }^{137} \mathrm{Cs}$ content at the CSIRO Land and Water laboratories in Canberra using HPGe detectors to count the $662 \mathrm{keV} \gamma$-rays that arise from ${ }^{137} \mathrm{Cs}$ decay [6]. Typically, a $4 \mathrm{pg}$ (i.e. $10^{10}$ atoms) ${ }^{242} \mathrm{Pu}$ spike was then added to a $10 \mathrm{~g}$ aliquot of each homogenised sample and the plutonium leached with hot nitric acid for $\sim 24$ hours. The acid solution was then purified using ion exchange columns and the ${ }^{239} \mathrm{Pu}$ and ${ }^{240} \mathrm{Pu}$ concentrations and ${ }^{240} \mathrm{Pu} /{ }^{239} \mathrm{Pu}$ ratio determined with AMS using the 14UD pelletron accelerator at the ANU $[7,8]$. The purified $\mathrm{Pu}$ fractions of a few selected replicate samples were separated off for electro-deposition [9] and analysis by $\alpha$ spectroscopy at the CSIRO laboratories.

\section{Results}

The ${ }^{239} \mathrm{Pu}$ concentrations, as determined by the AMS measurements, are presented in figure 2 and table A.1 as a function of soil depth for all eight cores. The profiles for samples T001 - T004 show maximum concentrations typical of those seen elsewhere in Australia [10-13], but which peak closer to the surface and only penetrate to around a quarter of the usual depth. This latter behaviour can most likely be attributed to the dry, desert-like environment of the area. Samples T006 - T008, on the other hand, show progressively larger surface maxima, reaching over $400 \mathrm{mBq}{ }^{239} \mathrm{Pu} / \mathrm{g}$ at site T008. These profiles also peak very close to the surface and have relatively small penetration depths. The depth profile for sample T005 however, shows very little $\mathrm{Pu}$, and suggests that the soil at this site has either been removed or buried by the addition of $>10 \mathrm{~cm}$ of topsoil: given the extensive activities but poorly documented early history of the area it is quite plausible that this was the case (see below).

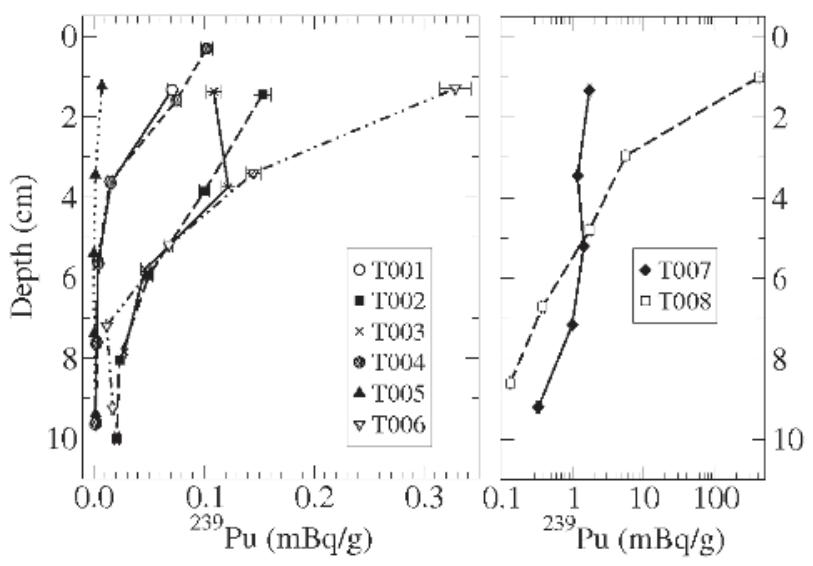

Figure 2. Soil depth profiles from alongside the Maralinga test site access road. Note the log scale for sites T007 and T008.

The ${ }^{240} \mathrm{Pu} /{ }^{239} \mathrm{Pu}$ atom ratio for each sample location, determined from the weighted average of all depth increments, is listed in table land plotted in figure 3 as a function of distance from the Taranaki test site. Our results for sites T007 and T008 are in good agreement 
Table 1. Plutonium and caesium activities and ratios in surface soils at Maralinga. Uncertainties include systematic and statistical errors and correspond to one standard deviation.

\begin{tabular}{|c|c|c|c|c|c|c|}
\hline \multirow[t]{2}{*}{ Sample } & \multirow[t]{2}{*}{${ }^{239} \mathrm{Pu}(\mathrm{mBq} / \mathrm{g})^{\mathrm{a}}$} & \multirow[t]{2}{*}{${ }^{240} \mathrm{Pu} /{ }^{239} \mathrm{Pu}$ atom ratio ${ }^{\mathrm{b}}$} & \multicolumn{2}{|c|}{${ }^{239+240} \mathrm{Pu}(\mathrm{mBq} / \mathrm{g})^{\mathrm{a}}$} & \multirow[t]{2}{*}{${ }^{137} \mathrm{Cs}(\mathrm{mBq} / \mathrm{g}){ }^{\mathrm{a}, \mathrm{c}}$} & \multirow{2}{*}{$\begin{array}{c}{ }^{137} \mathrm{C} /{ }^{239+240} \mathrm{Pu} \text { activity } \\
\text { ratio }{ }^{\mathrm{a}, \mathrm{c}}\end{array}$} \\
\hline & & & AMS & $\alpha$-spec. & & \\
\hline T001 & $0.071 \pm 0.005$ & $0.194 \pm 0.018$ & $0.123 \pm 0.007$ & & $3.15 \pm 0.16$ & $25.7 \pm 1.9$ \\
\hline T002 & $0.153 \pm 0.008$ & $0.144 \pm 0.008$ & $0.236 \pm 0.010$ & $0.244 \pm 0.008$ & $6.81 \pm 0.21$ & $28.9 \pm 1.4$ \\
\hline T003 & $0.109 \pm 0.007$ & $0.136 \pm 0.008$ & $0.154 \pm 0.009$ & & $3.15 \pm 0.15$ & $20.4 \pm 1.5$ \\
\hline T004 & $0.103 \pm 0.005$ & $0.133 \pm 0.009$ & $0.147 \pm 0.006$ & & $2.59 \pm 0.16$ & $17.6 \pm 1.3$ \\
\hline T005 & $0.007 \pm 0.001$ & $0.107 \pm 0.031$ & $0.010 \pm 0.001$ & & b.d.l. ${ }^{\mathrm{d}}$ & \\
\hline T006 & $0.328 \pm 0.014$ & $0.098 \pm 0.005$ & $0.444 \pm 0.016$ & $69 \pm 10^{\mathrm{e}}$ & $8.18 \pm 0.24$ & $18.4 \pm 0.8$ \\
\hline T007 & $1.734 \pm 0.073$ & $0.0412 \pm 0.002$ & $1.981 \pm 0.074$ & & $0.89 \pm 0.11$ & $0.45 \pm 0.06$ \\
\hline T008 & $408 \pm 17$ & $0.0532 \pm 0.002$ & $488 \pm 17$ & & $3.89 \pm 0.20$ & $0.0080 \pm 0.0004$ \\
\hline T008 & $0.136 \pm 0.006^{\mathrm{f}}$ & $0.066 \pm 0.005^{\mathrm{f}}$ & $0.169 \pm 0.007^{\mathrm{f}}$ & $0.956 \pm 0.026^{\mathrm{f}}$ & & \\
\hline
\end{tabular}

${ }^{\mathrm{a}}$ Uppermost depth increment

${ }^{\mathrm{b}}$ Average ratio for entire core

${ }^{\mathrm{c}}$ As measured on 31 Mar 2011

${ }^{\mathrm{d}}$ Below detection limit

${ }^{\mathrm{e}}$ The large error here is due to tailing of the very large ${ }^{239+240} \mathrm{Pu}$ peak propagating into the peak of the ${ }^{242} \mathrm{Pu}$ tracer

${ }^{\mathrm{f}}$ Lowermost $(77-95 \mathrm{~mm})$ depth increment only

with high resolution $\gamma$-ray spectrometry measurements (atom ratio: $0.027-0.046$ ) reported for Taranaki $[14,15]$. These earlier atom ratios were determined prior to the 1995-2000 (MARTAC) clean up when soil activities were considerably higher than is presently the case. Replicate samples also measured by AMS agreed within error for sites T001 - T006, as does the result for ${ }^{239+240} \mathrm{Pu}$ from a replicate sample at site T002 measured using $\alpha$-spectroscopy. The AMS replicates and $\alpha$ spectroscopy results for sites T006-T008 however, show variability that is greater than statistically expected. This is discussed in more detail below.

Table 1 also lists the ${ }^{239} \mathrm{Pu}$ and ${ }^{137} \mathrm{Cs}$ concentrations and the ${ }^{137} \mathrm{Cs} /{ }^{239+240} \mathrm{Pu}$ activity ratios for the uppermost depth increment from each site. Notably, the ${ }^{137} \mathrm{Cs}$ concentration is relatively constant between sites T001 and T008 and shows no obvious trend with distance from the test site, while that for ${ }^{239} \mathrm{Pu}$ increases by a factor of more than 5000, with the maximum close to the Taranaki test and trial site.

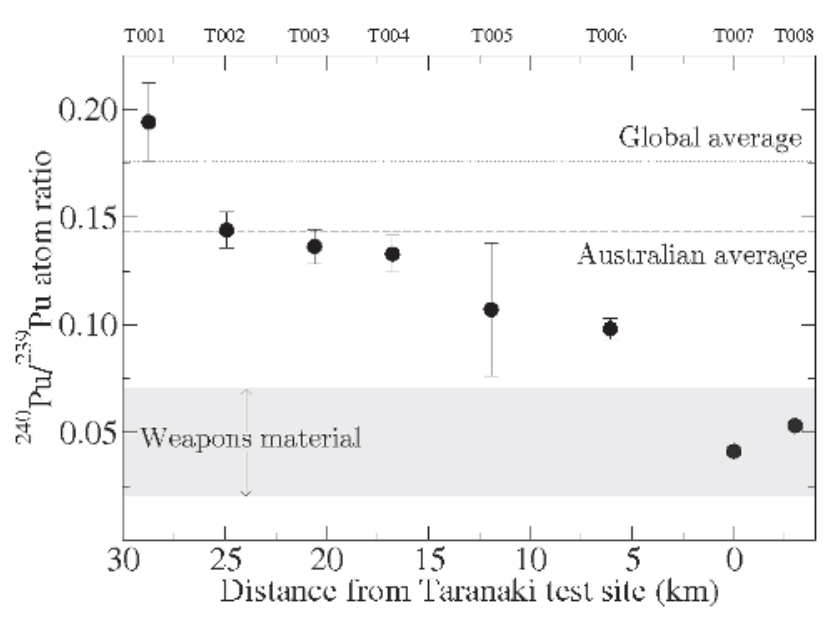

Figure 3. The ${ }^{240} \mathrm{Pu} /{ }^{239} \mathrm{Pu}$ atom ratio for sites $\mathrm{T} 001-\mathrm{T} 008$.

\section{Discussion}

Figure 2 shows the surface ${ }^{239} \mathrm{Pu}$ concentration increases by more than 3 orders of magnitude between sites T001T004 and site T008, which is close to the Taranaki test site. Figure 3 shows the ${ }^{240} \mathrm{Pu} /{ }^{239} \mathrm{Pu}$ ratios for sites T006T008 are well below the global fallout average of $\sim 0.18$ $[16,17]$, and also below the Australian average of $\sim 0.14$ [13]. The high concentrations and low ratios, which at sites $\mathrm{T} 007$ and $\mathrm{T} 008$ yield ${ }^{240} \mathrm{Pu} /{ }^{239} \mathrm{Pu}$ ratios consistent with undetonated weapons material [18], indicate that the $\mathrm{Pu}$ at these two sites is overwhelmingly derived from the safety trials which dispersed the weapons material using conventional explosives. The data for site T006 also suggests the presence of trials material, with ratios and concentrations between the two end members.

Although site T007 is the closest to the Taranaki test site, the $\mathrm{Pu}$ surface concentrations and inventory are significantly lower than at site T008. Furthermore, the ${ }^{137} \mathrm{Cs}$ concentration is also low at site T007, and the data therefore imply that material may also have been removed from this site. Site T007 is $\sim 480 \mathrm{~m}$ south-southwest of the detonation point, and while it appeared undisturbed at the time of sampling, is only $\sim 10 \mathrm{~m}$ from an area where earthworks have clearly taken place. Site $\mathrm{T} 008$, on the other hand is over $250 \mathrm{~m}$ from the nearest earthworks. Excluding sites T005 and T007, where the ${ }^{137} \mathrm{Cs}$ concentration shows similar behaviour to that of $\mathrm{Pu}$; i.e. is unusually low, the relatively constant ${ }^{137} \mathrm{Cs}$ concentration across the remaining sites $\left(1-10 \mathrm{mBq}{ }^{137} \mathrm{Cs}\right.$ per gram of soil) is similar to that reported elsewhere in Australia [5,19]. This indicates that local and regional fallout from the Australian weapons tests are not major contributors to the total Cs fallout at the sampling locations.

The ${ }^{239} \mathrm{Pu}$ and ${ }^{239+240} \mathrm{Pu}$ inventories for the eight sites, based on the AMS data, are listed in Table 2. Sites T001-T006 have inventories that are at the lower end of 
those typically observed in Australia, however there is not yet enough data to make meaningful comparisons. The inventories of sites T001-T004 show quite substantial variability from site to site, and at present we have no definitive explanation for this observation. The inventory at site T005 is particularly low, however there is some evidence from aerial photographs that indicate this site is within a few meters of past road works and the possibility that the soil surface has been disturbed cannot be ruled out, as is suggested above. Sites T007 and T008 have inventories that are far larger than observed elsewhere in Australia. Taken together the ${ }^{137} \mathrm{Cs}$ concentrations, ${ }^{240} \mathrm{Pu} /{ }^{239} \mathrm{Pu}$ ratios and $\mathrm{Pu}$ inventories indicate the dominant source of $\mathrm{Pu}$ at these sites is derived from local fallout derived from the safety trials of the 1960's. Further supportive evidence for this conclusion is provided by the ${ }^{240} \mathrm{Pu} /{ }^{239} \mathrm{Pu}$ and ${ }^{137} \mathrm{Cs} / 239+240 \mathrm{Pu}$ ratios, which are at a minimum at sites T007 (Taranaki) and T008, respectively. Both ratios return to values consistent with global fallout within 25 $\mathrm{km}$ of the test site.

The ${ }^{137} \mathrm{Cs} /{ }^{239+240} \mathrm{Pu}$ activity ratios at sites $\mathrm{T} 001$ and T002 are in good agreement with the (decay corrected) fallout ratios of 23.5 reported for Antarctica [20], our value of $24.7 \pm 1.4$ for the Herbert River, Australia [5], and with an estimated ratio of $\sim 28.6$, based on ${ }^{90} \mathrm{Sr}$ deposition and the total annual world-wide activity releases for ${ }^{90} \mathrm{Sr},{ }^{137} \mathrm{Cs}$ and ${ }^{239+240} \mathrm{Pu}$ [21]. Sites T007 and T008 give ${ }^{137} \mathrm{Cs} /{ }^{239+240} \mathrm{Pu}$ activity ratios that are much lower but are in good agreement with, and show similar variability to, those reported for Maralinga [14, 15]. The other sites show ${ }^{137} \mathrm{Cs} /{ }^{239+240} \mathrm{Pu}$ activity ratios intermediate between the global fallout and weapons test site values, reflecting the diminishing influence of the trials as the distance from the testing area increases.

Table 2. Plutonium inventories from Maralinga, determined using the measured densities $\left(\sim 1.6 \mathrm{~g} . \mathrm{cm}^{3}\right)$ for each increment.

\begin{tabular}{crr}
\hline Sample & $\begin{array}{c}{ }^{239} \mathrm{Pu} \text { Inventory } \\
\left(\mathrm{mBq} / \mathrm{cm}^{2}\right)\end{array}$ & $\begin{array}{c}{ }^{239+240} \mathrm{Pu} \text { Inventory } \\
\left(\mathrm{mBq} / \mathrm{cm}^{2}\right)\end{array}$ \\
\hline $\mathrm{T} 001$ & $0.421 \pm 0.005$ & $0.729 \pm 0.007$ \\
$\mathrm{~T} 002$ & $1.43 \pm 0.01$ & $2.17 \pm 0.01$ \\
$\mathrm{~T} 003$ & $1.08 \pm 0.01$ & $1.62 \pm 0.01$ \\
$\mathrm{~T} 004$ & $0.496 \pm 0.007$ & $0.750 \pm 0.008$ \\
$\mathrm{~T} 005$ & $0.040 \pm 0.001$ & $0.056 \pm 0.001$ \\
$\mathrm{~T} 006$ & $1.90 \pm 0.02$ & $2.60 \pm 0.02$ \\
$\mathrm{~T} 007$ & $21.2 \pm 0.1$ & $24.5 \pm 0.1$ \\
$\mathrm{~T} 008$ & $1241 \pm 17$ & $1483 \pm 17$ \\
\hline
\end{tabular}

The variability in the replicate samples at sites T006T008 suggests the sampled material is not homogenous. However, at site T006 the disagreement between the AMS and $\alpha$-spectroscopy replicates is greater than a factor of 200; and at site T008 replicates differ by more than a factor of 5. It is unlikely that such differences could be the result of a simple failure to mix the sample material adequately prior to separation of each sample aliquot. The presence of sub-millimetre plutoniumbearing particles is however, well documented at Maralinga [4], and given the proximity of these sampling locations to the Vixen B safety trials, it is suspected that such "hot particles" are the likely source of the discrepancies observed in the present data.

\section{Conclusion}

The ${ }^{137} \mathrm{Cs},{ }^{239} \mathrm{Pu}$ and ${ }^{240} \mathrm{Pu}$ data from sites T001 and T002 indicate that tropospheric fallout deposition at distances greater than $\sim 25 \mathrm{~km}$ to the south of the test area has been negligible. Our data are consistent with that of global fallout in Australia, and are also consistent with fallout distribution maps from the Australian tests [22, 23] which indicate the bulk of the regional fallout from the Maralinga weapons detonations was to the north and east of the test site. The data from sites T006-T008 however, show clear signatures of local fallout $\mathrm{Pu}$ derived from the safety trials, with indications of the presence of "hot particles" of $\mathrm{Pu}$ bearing material. The ${ }^{137} \mathrm{Cs} /{ }^{239+240} \mathrm{Pu}$ ratio, which changes by over 3 orders of magnitude across the present sampling sites, appears to provide the most sensitive probe of the presence of local or regional fallout, however only the ${ }^{240} \mathrm{Pu} /{ }^{239} \mathrm{Pu}$ ratio provides definitive information on the source of the Pu. Excluding sites T005-T008, the ${ }^{239} \mathrm{Pu}$ inventories are at the low end of the range typically observed in Australia, and show greater variability than expected. Importantly from the point of view of using $\mathrm{Pu}$ as a tracer of soil movement, the contribution to the $\mathrm{Pu}$ inventories from the weapons tests and safety trials does not appear to be significant at distances greater than $10 \mathrm{~km}$ to the south of the test site area. The variability in the inventories however, could be important and needs to be understood, as does the extent of the impacted area in other directions. Further work is in planning to address these issues.

\section{Acknowledgements}

The authors gratefully acknowledge B. Ryan (Environmental Research Institute of the Supervising Scientist), and C. Doering (Australian Radiation Protection and Nuclear Safety Agency) for providing the soil samples.

\section{References}

1. K.R. Peterson, Health Physics, 18, 357 (1970)

2. R.W. Holloway, D.W. Hayes, Environ. Sci. Technol. 16, 127 (1982)

3. C.C. Wendel, D.H. Oughton, O.C. Lind, L. Skipperud, L.K. Fifield, E. Isaksson, S.G. Tims, B. Salbu, Sci. Total Environ. 461-462, 734 (2013)

4. S. Long, L. Martin, S. Baylis, J. Fry, J. Environ. Radioact. 76, 207 (2004)

5. S.E. Everett, S.G. Tims, G.J. Hancock, R. Bartley, L.K. Fifield, J. Environ. Radioact. 99, 383 (2008)

6. A.S. Murray, R. Marten, A. Johnston, P. Martin, J. Radioanal. Nucl. Chem. 115, 263 (1987)

7. L.K. Fifield, Quaternary Geochronology 3, 276 (2008)

8. S.G. Tims, L.K. Fifield, EPJ Web of Conferences 35, 01002 (2012) 
9. L. Halstadius, Nucl. Instr. Meth. 223, 226 (1984)

10. S.G. Tims, S.E. Everett, L.K. Fifield, G.J. Hancock, R. Bartley, Nucl. Instr. Meth. Phys. Res. B 268, 1150 (2010)

11. W.T. Hoo, L.K. Fifield, S.G. Tims, T. Fujioka, N. Mueller, J. Environ. Radioact. 102, 937 (2011)

12. R. Lal, S.G. Tims, L.K. Fifield, R.J. Wasson, D. Howe, Nucl. Instr. Meth. Phys. Res. B 294, 577 (2013)

13. S. G. Tims, L. K. Fifield, G.J. Hancock, R. R. Lal, W. T. Hoo, Nucl. Instr. Meth. Phys. Res. B 294, 636 (2013)

14. K.H. Lokan, Technical report ARL/TR070 Australian Radiation Laboratory (1985)

15. P.A. Burns, M.B. Cooper, J.C. Duggleby, J.F. Mika, G.A. Williams, Technical report ARL/TR075 Australian Radiation Laboratory (1986)

16. P.W. Krey, E.P. Hardy, C. Pachucki, F. Rourke, J. Coluzza, W.K. Benson, in: Proceedings of a
Symposium on Transuranium Nuclides in the Environment, IAEA-SM-199/39, Vienna: IAEA, 671 (1976).

17. J.M. Kelley, L.A. Bond, T.M. Beasley, Sci. Tot. Environ 237/238, 483 (1999)

18. T. Warneke, I.W. Croudace, P.E. Warwick, R.N. Taylor, Earth Planet. Sci. Lett. 203, 1047 (2002)

19. P.J. Wallbrink, C.E. Martin, C.J. Wilson, Soil Till. Res. 69, 53 (2003)

20. M. Koide, R. Michel, E.D. Goldberg, M.M. Herron, C.C. Langway Jr., Earth Planet. Sci. Lett. 44, 205 (1979)

21. UNSCEAR, Sources and Effects of Ionizing Radiation, vol. 1. Annex C, United Nations, New York, 158 (2000)

22. W.A.S. Butement, L.J. Dwyer, L.H. Martin, D.J. Stevens, E.W. Titterton, Aust. J. Sci 21, 63 (1958)

23. L.J. Dwyer, L.H. Martin, D.J. Stevens, E.W. Titterton, Aust. J. Sci 22, 97 (1959)

Table A.1. Plutonium concentrations, as determined by AMS, for the samples from the present work. Replicate samples are indicated with $\mathrm{a} *$.

\begin{tabular}{|c|c|c|c|}
\hline Sample & Depth $(\mathrm{cm})$ & ${ }^{239} \mathrm{Pu}(\mathrm{mBq} / \mathrm{g})$ & ${ }^{240} \mathrm{Pu}(\mathrm{mBq} / \mathrm{g})$ \\
\hline T001_A & $0-2.7$ & $0.071 \pm 0.005$ & $0.051 \pm 0.005$ \\
\hline T001 B & $2.7-4.7$ & $0.016 \pm 0.002$ & $0.012 \pm 0.002$ \\
\hline T001_B* & $2.7-4.7$ & $0.015 \pm 0.001$ & $0.014 \pm 0.002$ \\
\hline T001_C & $4.7-6.7$ & $0.004 \pm 0.001$ & $0.003 \pm 0.002$ \\
\hline T001_D & $6.7-$ & $0.002 \pm 0.001$ & $0.0013 \pm 0.0006$ \\
\hline T001_E & $8.7-10.7$ & $0.0014 \pm 0.0004$ & $0.0005 \pm 0.0004$ \\
\hline T002_A & $0-2$ & $0.153 \pm 0.008$ & $0.083 \pm 0.006$ \\
\hline T00 & $2.9-4.8$ & $0.105 \pm 0.005$ & $0.055 \pm 0.004$ \\
\hline T002_B* & $2.9-4.8$ & $0.096 \pm 0.005$ & $0.043 \pm 0.003$ \\
\hline T002_C & 4.8 & $0.050 \pm 0.004$ & $0.025 \pm 0.004$ \\
\hline T002 & $7.1-9.0$ & $0.023 \pm 0.002$ & $0.012 \pm 0.002$ \\
\hline T00 & $9.0-$ & $0.021 \pm 0.002$ & $0.012 \pm 0.002$ \\
\hline T003_A & $0-2.8$ & $0.109 \pm 0.007$ & $0.045 \pm 0.005$ \\
\hline T00 & $2.8-4.8$ & $0.158 \pm 0.008$ & $0.081 \pm 0.005$ \\
\hline $\mathrm{T} 00$ & $2.8-4.8$ & $0.106 \pm 0.005$ & $0.060 \pm 0.004$ \\
\hline T003_C & $4.8-6.9$ & $0.046 \pm 0.004$ & $0.025 \pm 0.004$ \\
\hline T003_D & $6.9-8$ & $0.028 \pm 0.002$ & $0.015 \pm 0.002$ \\
\hline T003_E & $8.9-10.9$ & b.d.1 & b.d.1 \\
\hline T004_A & $0-0.6$ & $0.094 \pm 0.005$ & $0.042 \pm 0.003$ \\
\hline T004_A* & $0-0.6$ & $0.115 \pm 0.006$ & $0.045 \pm 0.004$ \\
\hline T004_B & $0.6-2.6$ & $0.080 \pm 0.004$ & $0.040 \pm 0.003$ \\
\hline T004_B* & $0.6-2.6$ & $0.069 \pm 0.005$ & $0.034 \pm 0.004$ \\
\hline T004_C & $2.6-4.6$ & $0.014 \pm 0.001$ & $0.010 \pm 0.002$ \\
\hline T004_C C & $2.6-4.6$ & $0.015 \pm 0.001$ & $0.008 \pm 0.001$ \\
\hline T004_D & $4.6-6.6$ & $0.0040 \pm 0.0005$ & $0.0036 \pm 0.0008$ \\
\hline T004_D* & $4.6-6.6$ & $0.0028 \pm 0.0007$ & $0.0026 \pm 0.0009$ \\
\hline T004_E & $6.6-8.6$ & $0.0022 \pm 0.0005$ & $0.0013 \pm 0.0006$ \\
\hline T004_E* & $6.6-8.6$ & $0.0034 \pm 0.0006$ & $0.0020 \pm 0.0007$ \\
\hline T004_F & $8.6-10.6$ & $0.0020 \pm 0.0005$ & $0.0014 \pm 0.0006$ \\
\hline T004_F* & $8.6-10.6$ & $0.0023 \pm 0.0007$ & $0.0006 \pm 0.0006$ \\
\hline
\end{tabular}

\begin{tabular}{|c|c|c|c|}
\hline Sample & Depth $(\mathrm{cm})$ & ${ }^{239} \mathrm{Pu}(\mathrm{mBq} / \mathrm{g})$ & ${ }^{240} \mathrm{Pu}(\mathrm{mBq} / \mathrm{g})$ \\
\hline T005_A & $0-2.5$ & $0.0062 \pm 0.0009$ & $0.0021 \pm 0.0007$ \\
\hline T005_A* & $0-2.5$ & $0.0081 \pm$ & $0.0030 \pm 0.0007$ \\
\hline T005_B & $2.5-4.4$ & $0.0013 \pm 0.0003$ & $0.0006 \pm 0.0004$ \\
\hline T005_B* & $2.5-4.4$ & $0.0017 \pm 0.0004$ & $0.0005 \pm 0.0003$ \\
\hline T005_C & $4.4-6.4$ & $0.0005 \pm 0.0002$ & b.d.1 \\
\hline T005_C & $4.4-6.4$ & $0.0001 \pm 0.0001$ & b.d.1 \\
\hline T005_D & $6.4-8.4$ & $0.0003 \pm 0.0001$ & b.d.1 \\
\hline T005_E & $8.4-10.4$ & $0.0015 \pm 0.0004$ & $0.0012 \pm 0.0006$ \\
\hline T006_A & $0-2.6$ & $0.328 \pm 0.014$ & $0.116 \pm 0.006$ \\
\hline T006 B & $2.6-4.2$ & $0.152 \pm 0.007$ & $0.057 \pm 0.003$ \\
\hline T006_B* & $2.6-4.2$ & $0.138 \pm 0.007$ & $0.060 \pm 0.004$ \\
\hline T006 C & $4.2-6.2$ & $0.068 \pm 0.004$ & $0.024 \pm 0.002$ \\
\hline T006_D & $6.2-8.2$ & $0.0117 \pm$ & $0.0054 \pm$ \\
\hline T006 E & $8.2-10.3$ & $0.017 \pm 0.001$ & $0.006 \pm 0.001$ \\
\hline T007 A & $0-2.7$ & $1.734 \pm 0.073$ & $0.247 \pm 0.012$ \\
\hline T007 B & $2.7-4.3$ & $1.424 \pm 0.060$ & $0.218 \pm 0.009$ \\
\hline T007_B ${ }^{*}$ & $2.7-4.3$ & $1.055 \pm 0.045$ & $0.153 \pm 0.009$ \\
\hline T007_C & $4.3-6.2$ & $1.446 \pm 0.062$ & $0.217 \pm 0.011$ \\
\hline T007_D & $6.2-8.2$ & $1.001 \pm 0.042$ & $0.165 \pm 0.009$ \\
\hline T007 E & $8.2-10.3$ & $0.335 \pm 0.016$ & $0.053 \pm 0.006$ \\
\hline T008 A & $0-2.0$ & $408 \pm 17$ & $80 \pm 3$ \\
\hline T008_B & $2.0-3.9$ & $4.76 \pm 0.20$ & $0.92 \pm 0.04$ \\
\hline T008_B* & $2.0-3.9$ & $18.1 \pm 0.8$ & $2.80 \pm 0.12$ \\
\hline T008_C & $3.9-5.7$ & $1.739 \pm 0.073$ & $0.329 \pm 0.018$ \\
\hline T008 D & $5.7-7.7$ & $0.386 \pm 0.017$ & $0.082 \pm 0.005$ \\
\hline T008 E & $7.7-9.5$ & $0.136 \pm$ & $0.033 \pm$ \\
\hline
\end{tabular}

